\title{
Placental Transfer and Fetal Effects of Maternal Sodium $\beta$-Hydroxybutyrate Infusion in the Baboon
}

\author{
JOHN B. PATON, LYNNE L. LEVITSKY, AND DAVID E. FISHER \\ Divisions of Neonatology and Metabolism, Department of Pediatrics, Michael Reese Hospital and Medical \\ Center; University of Chicago, Pritzker School of Medicine, Chicago, Illinois 60616
}

\begin{abstract}
We examined the effects of maternal sodium $\beta$-hydroxybutyrate $(\mathrm{NaBOHB})$ on the primate fetus to investigate the impact of ketosis not associated with acidosis on fetal metabolism. After a loading dose $(600 \mathrm{mg} /$ $\mathrm{kg})$, NaBOHB was infused for $70 \mathrm{~min}(300 \mathrm{mg} / \mathrm{kg} \cdot \mathrm{hr})$ into the maternal femoral vein of eight pregnant baboons, and placental transfer and fetal and maternal metabolic changes were observed during an acute experimental protocol. Maternal arterial levels rose from $0.70 \pm 0.21$ to $5.42 \pm 0.93 \mathrm{mM}(p<0.001)$, and fetal arterial levels from $0.34 \pm 0.09$ to $2.76 \pm 0.64 \mathrm{mM}(p<0.01)$. A maternalfetal gradient of approximately 2:1 was observed in both baseline and steady-state infusion conditions and is similar to the human maternal-fetal ketone gradient. This is in contrast to the sheep where significantly higher gradients have been described. The elevated lactate, from $1.90 \pm$ 0.34 to $2.88 \pm 0.54 \mathrm{mM}(p<0.05)$ and somewhat decreased $\mathrm{pO}_{2}$ values in the fetus from $54.8 \pm 8.9$ to $45.0 \pm$ $3.8 \mathrm{~mm} \mathrm{Hg}(p>0.05<0.1)$, without change in oxygen consumption ( $2.00 \pm 0.28$ versus $1.73 \pm 0.15 \mathrm{mM} / \mathrm{min})$ are features common to conditions of increased levels of fetal energy substrate. NaBOHB does not appear to contribute to oxidative energy metabolism of the whole fetus but may contribute to lipid stores. The significance of higher levels of $\mathrm{BOHB}$ in the primate fetus compared to the sheep fetus remains to be elucidated. (Pediatr Res 25:435-439, 1989)
\end{abstract}

Abbreviations

BOHB, $\beta$-hydroxybutyrate

NaBOHB, sodium $\beta$-hydroxybutyrate

Ketoacidosis during human pregnancy has deleterious effects on both mother and fetus. Serious consequences for the fetus include increased mortality and increased prevalences of malformations and intellectual deficits (1-3). Human placental ketone body transport has not been well studied. A number of reports have described placental transfer and metabolic effects of BOHB infusion in the pregnant sheep. However, the human maternalfetal gradient for ketones, 2:1 (4), is different from that reported for the sheep, 7-10:1 (5). The sheep placenta is epitheliochorial in contrast to the hemochorial placentation of the primates. To better define the metabolic effects of hyperketonemia in the

Received February 8, 1988: accepted December 8, 1988.

Mailing address John B. Paton, Department of Pediatrics, Divisions of Neonatology and Metabolism. Michael Reese Hospital and Medical Center, Lake Shore Drive at 31 st Street, Chicago, IL 60616.

Supported in part by USPHS HD, 22891, Michael Reese Research Institute, Department of Pediatrics Funds and Infants' Aid. nonhuman primate, we studied placental transfer of ketones during an acute experimental infusion of $\mathrm{NaBOHB}$ into the maternal circulation of eight pregnant baboons in late gestation.

\section{MATERIALS AND METHODS}

Baboons of known gestational age were obtained from the Biologic Resources Laboratory, University of Illinois, Chicago, and studied between 164 and 171 d of gestation (term $184 \mathrm{~d}$ ). Individually caged pregnant animals had food and water removed $16 \mathrm{~h}$ before surgery. After initial tranquilization with phencyclidine and endotracheal intubation, anesthesia was maintained with halothane and an $80 \%$ oxygen-air mixture. This mixture increases maternal oxygenation $(303 \pm 14 \mathrm{~mm} \mathrm{Hg})$, but was used so that data would be comparable to previously published acute studies in the baboon (6-8). As previously described (6-8), fetal catheters were placed in the femoral vein, femoral artery, and umbilical vein. Maternal catheters were placed in a femoral artery and femoral vein. The experimental protocol lasted $3 \frac{1}{2} \mathrm{~h}$, beginning with the start of the antipyrine infusion into the fetal femoral vein. During the 1 st $h$, fetal catheter placement was completed. As described in Table 1, during the next 80 min four sets of samples were drawn from the fetal femoral artery, umbilical vein and maternal artery for substrate analyses. Additional sample sets were obtained for antipyrine and blood gas analyses. The umbilical vein was sampled for glucose, ketones, antipyrine, and blood gases only.

During the last period of the protocol, a maternal loading intravenous infusion of $600 \mathrm{mg} / \mathrm{kg}$ of $\mathrm{NaBOHB}$ was administered over $10 \mathrm{~min}$ and an infusion continued at $300 \mathrm{mg} / \mathrm{kg} \cdot \mathrm{hr}$ for the next $70 \mathrm{~min}$. During this period, the earlier sampling protocol was repeated. Four sets of blood samples were drawn for substrate analyses. Additional sample sets were obtained for antipyrine and blood gas analyses. The sampling protocol used a total of $26 \mathrm{~mL}$ of fetal blood. To maintain fetal blood vol, maternal blood was collected at the beginning of the protocol. Fetal blood samples were then replaced vol for vol with maternal blood after each sampling. At the end of the protocol, the fetus was delivered and killed humanely. The mother was returned to the breeding colony after surgical repair and recovery.

\section{ANALYSES}

Plasma samples were analyzed for glucose using a glucose oxidase, oxygen electrode technique (Beckman Instruments Inc.. Fullerton CA) and for glycerol (9), lactate (10), pyruvate (11). alanine (11), and BOHB (12), using enzymatic fluorometric methods (13). Samples for pyruvate were analyzed immediately. Others were frozen at $-70^{\circ} \mathrm{C}$ until measurement. All samples for enzymatic analysis, except those for glucose, were assayed after preparation of 1:10 dilution of a protein-free filtrate using Cen- 
triflo membrane cones (CF-50, Amicon Corp. Scientific Sys. Div., Danvers, MA). All analyses of each sample were performed in triplicate and each replicate set was analyzed in the same assay. Replicate assays were rejected and repeated if determinations varied more than $5 \%$ from the mean. Mean values for these determinations were reported.

Enzymes for substrate analyses were obtained from Boehringer-Mannheim Biochemicals, NY (glycerokinase, glycerophosphate dehydrogenase) and Sigma Chemical Co., St. Louis, MO (lactate dehydrogenase, D- $\beta$-hydroxybutyrate, glutamic-pyruvic transaminase). Reagents used to construct standard curves were purchased from Sigma (lactic acid, DL- $\beta$-hydroxybutyrate, $\alpha$-ketoglutarate, alanine, pyruvate) and Sargent-Welch, Chicago, IL (glycerol). NADH and NAD were purchased from Sigma.

Table 1. Experimental protocol*

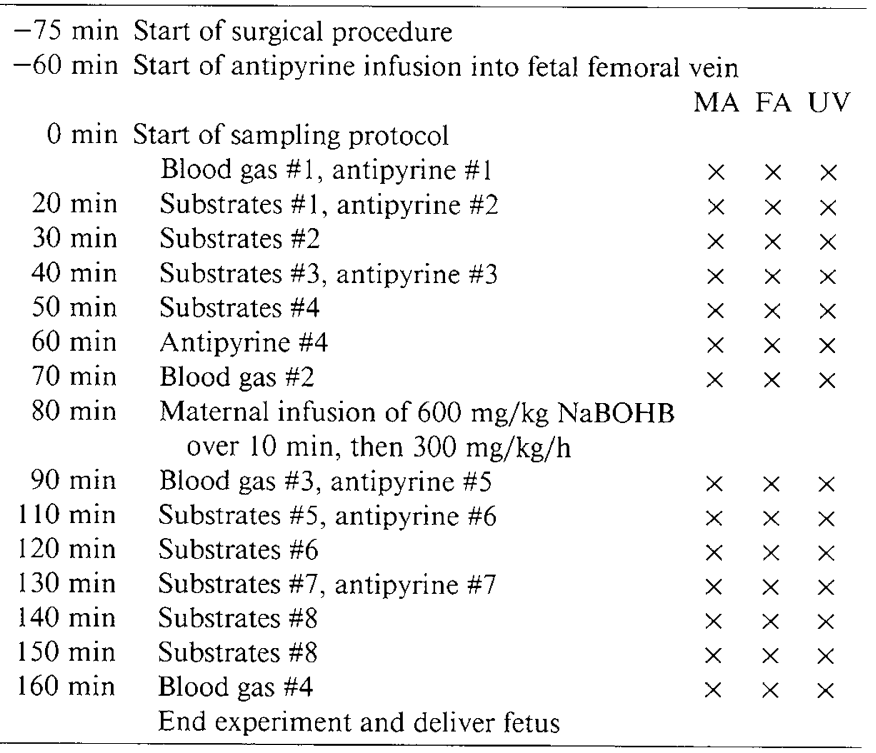

* Abbreviations: MA, maternal femoral artery; FA, fetal femoral artery; UV, umbilical vein.
Fluorometric analyses were performed on an Aminco-Bowman SPF-125 spectrophotofluorometer.

Antipyrine was measured colorimetrically using an AutoAnalyzer (Technicon Instruments Corp., Tarrytown, NY). Blood gases $\left(\mathrm{pH}, \mathrm{PCO}_{2}\right.$, and $\mathrm{PO}_{2}$ ) were determined at $37^{\circ} \mathrm{C}$ using Radiometer (Radiometer America Inc., Westlake, $\mathrm{OH}$ ) electrodes and meter, PHM71, and oxygen content measured with a $\mathrm{Lex}-\mathrm{O}_{2-}$ Con (Lexington Instruments Corp., Waltham, MA).

Data obtained before and during $\mathrm{NaBOHB}$ infusion are presented as mean \pm SEM and were compared by ANOVA (15).

\section{RESULTS}

Before $\mathrm{NaBOHB}$ infusion, fetal concentration of alanine, lactate, and pyruvate were higher than maternal levels $(p<0.05)$ (Table 2). Fetal glucose concentrations were the same as maternal and fetal ketone levels and were significantly lower than maternal values $(\mathrm{p}<0.05)$.

Maternal infusion of $\mathrm{NaBOHB}$ resulted in an increase in maternal arterial levels from $0.70 \pm 0.21$ to $5.42 \pm 0.95 \mathrm{mM}(p$ $<0.001)$ and in fetal arterial levels from $0.34 \pm 0.09$ to $2.76 \pm$ $0.64 \mathrm{mM}(p<0.01)$. During NaBOHB infusion, maternal and fetal lactate and pyruvate increased significantly $(p<0.05)$; glucose, alanine, and glycerol did not change. Maternal and fetal levels of ketones (BOHB and acetoacetate) increased during infusion so that the preinfusion maternal-fetal gradient was maintained. In addition, both fetal and maternal lactate and pyruvate increased, so that the fetal:maternal relationship remained the same.

Maternal acid-base status (Table 3) was maintained within normal limits before and did not change during $\mathrm{NaBOHB}$ infusion. The elevated maternal and fetal $\mathrm{PO}_{2}$ values were due to the oxygen enriched inhalation mixture. Fetal acid base values were consistent with the mild mixed metabolic and respiratory acidosis seen during acute experimental protocols. Fetal acid-base status did not change, but umbilical vein $\mathrm{PO}_{2}$ and $\mathrm{O}_{2}$ content showed a trend towards lower values $(p>0.05<0.1)$ during NaBOHB infusion.

Umbilical blood flow $148 \pm 17.8 \mathrm{~mL} / \mathrm{kg}$. min was within the normal range for the late gestation baboon fetus and did not

Table 2. Maternal and fetal blood levels of ketones, glucose, alanine, lactate, pyruvate and glycerol before and during infusion of $\mathrm{NaBOHB}{ }^{*}$

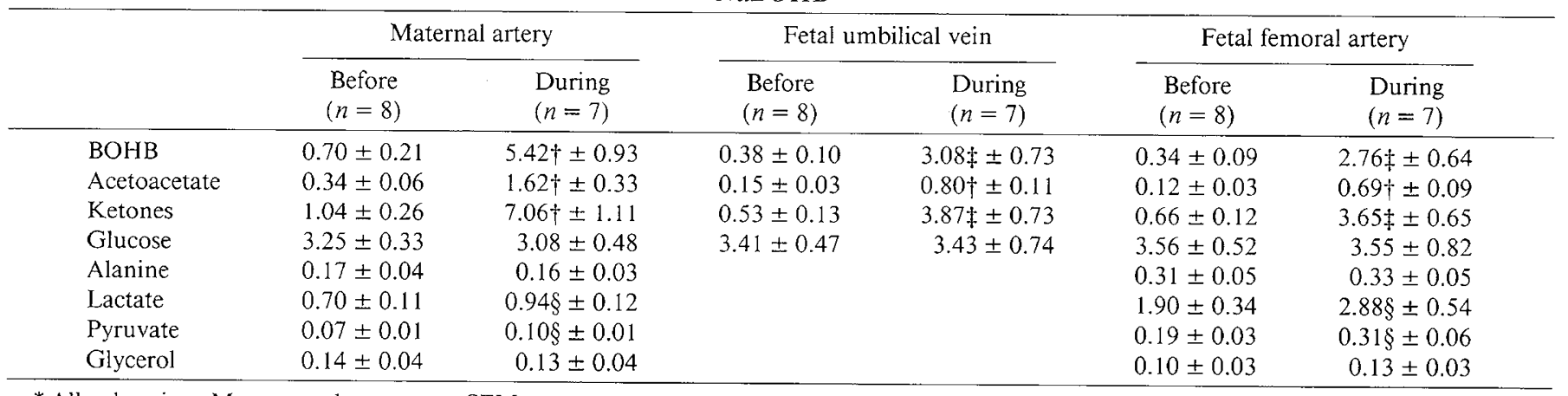

* All values in $\mathrm{mM}$ expressed as mean \pm SEM.

$\dagger$ In before-during comparisons: $p<0.001$.

$\ddagger$ In before-during comparisons: $p<0.01$.

$\S$ In before-during comparisons: $p<0.05$.

Table 3. Maternal and fetal $\mathrm{pH}$ and blood gas values before and during infusion of NaBOHB*

\begin{tabular}{|c|c|c|c|c|c|c|c|}
\hline & \multicolumn{3}{|c|}{ Maternal artery } & \multicolumn{4}{|c|}{ Fetal umbilical vein } \\
\hline & $\mathrm{pH}$ & $\begin{array}{c}\mathrm{PO}_{2} \\
\mathrm{~mm} \mathrm{Hg}\end{array}$ & $\begin{array}{c}\mathrm{PCO}_{2} \\
\mathrm{~mm} \mathrm{Hg}\end{array}$ & $\mathrm{pH}$ & $\begin{array}{c}\mathrm{PO}_{2} \\
\mathrm{~mm} \mathrm{Hg}\end{array}$ & $\begin{array}{c}\mathrm{PCO}_{2} \\
\mathrm{~mm} \mathrm{Hg}\end{array}$ & $\begin{array}{c}\mathrm{O}_{2} \text { content } \\
\mathrm{mM}\end{array}$ \\
\hline Before $(n=8)$ & $7.39 \pm 0.01$ & $303.2 \pm 13.8$ & $35.3 \pm 1.6$ & $7.27 \pm 0.02$ & $54.8 \pm 8.9$ & $44.2 \pm 7.8$ & $4.75 \pm 0.47$ \\
\hline During $(n=7)$ & $7.41 \pm 0.02$ & $302.1 \pm 29.9$ & $36.9 \pm 1.3$ & $7.27 \pm 0.03$ & $45.0+ \pm 3.8$ & $47.8 \pm 2.9$ & $4.31 \pm 0.43$ \\
\hline
\end{tabular}

* All values expressed as mean \pm SEM. In before-during comparison: $p>0.05<0.1$. 
change significantly during NaBOHB infusion (Table 4). Fetal arteriovenous substrate concentration differences were multiplied by umbilical blood flow to calculate oxygen, glucose, and ketone turnover by the fetus (Table 5). During the maternal $\mathrm{NaBOHB}$ infusion, fetal ketone uptake increased 6-fold from $9.12 \pm 1.84$ to $61.6 \pm 11.1 \mu \mathrm{mol} / \mathrm{kg} \cdot \mathrm{min}$ without change in oxygen consumption or net glucose transfer. Oxygen delivery to the fetus (umbilical vein flow $\times$ umbilical vein oxygen content) did not change significantly. It was $0.71 \pm 0.12$ before and 0.61 $\pm 0.14 \mathrm{mM} / \mathrm{kg} \cdot \mathrm{min}$ during $\mathrm{NaBOHB}$ infusion.

\section{DISCUSSION}

As shown in Figure 1, the baboon fetus maintains a BOHB level of $0.38 \pm 0.10 \mathrm{mM}$, about one-half that of the mother, 0.70 $\pm 0.21 \mathrm{mM}$. When maternal levels are elevated to $5.42 \pm 0.93$ $\mathrm{mM}$, this ratio is rapidly resumed with fetal levels of $3.08 \pm 0.73$ $\mathrm{mM}$. In contrast, Morriss et al. (5) demonstrated maternal BOHB

Table 4. Gestational age, maternal and fetal wt, and fetal umbilical blood flow*

\begin{tabular}{|c|c|c|c|c|c|}
\hline \multirow{2}{*}{\multicolumn{2}{|c|}{$\begin{array}{c}\text { Maternal } \\
\text { wt (kg) }\end{array}$}} & \multirow{2}{*}{$\begin{array}{c}\text { Gestational } \\
\text { age (d) }\end{array}$} & \multirow{2}{*}{ Fetal wt $(\mathrm{g})$} & \multicolumn{2}{|c|}{ Umbilical blood flow } \\
\hline & & & & $\mathrm{mL} / \mathrm{min}$ & $\mathrm{mL} / \mathrm{kg} \cdot \min$ \\
\hline $\begin{array}{l}\text { Before } \\
\text { During }\end{array}$ & $15.5 \pm 0.3$ & $167.6 \pm 0.7$ & $822.5 \pm 37.6$ & $\begin{array}{l}111.1 \pm 11 . \\
112.1 \pm 20 .\end{array}$ & $\begin{array}{l}147.5 \pm 17.8 \\
131.4 \pm 20.4\end{array}$ \\
\hline
\end{tabular}

* All values expressed as mean $\pm \mathrm{SEM}$. levels 7-10 times those found in the fetus in both fed and fasting states in chronically catheterized sheep (Table 6). Also in the sheep (16), during acute induced ketonemia after $2 \mathrm{~h}$ of BOHB infusion, the maternal-fetal gradient was nearly 20 times that seen in the primate. The peak maternal level reported was 6.93 $\pm 1.32 \mathrm{mM}$, and the peak fetal level was $0.15 \pm 0.03 \mathrm{mM}$. The maternal-fetal gradient in these experiments by Miodovnik et al. (16) appears to be increased over that reported by Morriss et al. (5), perhaps because of failure to reach a maternal steady state concentration during the experiment. In that study, as in ours, ketonemia was induced by infusion of a potential alkalinizing agent, NaBOHB. In human neonates, Paterson et al. (4) reported cord blood ketone levels of $0.47 \pm 0.11 \mathrm{mM}$ at the time of normal delivery; paired maternal levels were $0.93 \pm 0.19 \mathrm{mM}$. There was a similar maternal-fetal ratio when maternal levels were elevated. At midgestation, results were similar (17): maternal levels were $0.49 \pm 0.06 \mathrm{mM}$ and fetal levels were $0.25 \pm 0.03$ $\mathrm{mM}$.

The data presented here were obtained during acute experiments. The high level of maternal oxygenation $(303 \pm 14 \mathrm{~mm}$ $\mathrm{Hg}$ ) was used to obtain experimental conditions comparable to those previously reported in the baboon preparation $(7,8)$. The acid-base data indicate a mild maternal metabolic acidosis and a mixed acidosis in the fetus. Before $\mathrm{BOHB}$ infusion in this acute experimental protocol, the baboon fetus showed evidence of stress, with fetal arterial glucose elevated above maternal arterial levels; this difference was not significant. During the experiment, the lack of change of maternal or fetal glucose levels indicated

Table 5. Net fetal exchange of oxygen, glucose and ketones before and during infusion of NaBOHB*

\begin{tabular}{|c|c|c|c|c|c|c|}
\hline & \multicolumn{2}{|c|}{ Fetal oxygen uptake } & \multicolumn{2}{|c|}{ Net glucose loss by fetus } & \multicolumn{2}{|c|}{ Ketone uptake } \\
\hline & $\mathrm{mM}$ & $\mathrm{mL} / \mathrm{kg} \cdot \min$ & $\mathrm{mM}$ & $\mu \mathrm{mol} / \mathrm{kg} \cdot \min$ & $\mathrm{mM}$ & $\mu \mathrm{mol} / \mathrm{kg} \cdot \min$ \\
\hline Before $(n=8)$ & $2.00 \pm 0.28$ & $5.90 \pm 0.82$ & $0.10 \pm 0.06$ & $14.40 \pm 9.30$ & $0.06 \pm 0.00$ & $9.12 \pm 1.84$ \\
\hline
\end{tabular}

* All values expressed as mean \pm SEM.

$\dagger$ In before-during comparisons: $p<0.001$

$\ddagger$ In before-during comparisons: $p<0.01$.

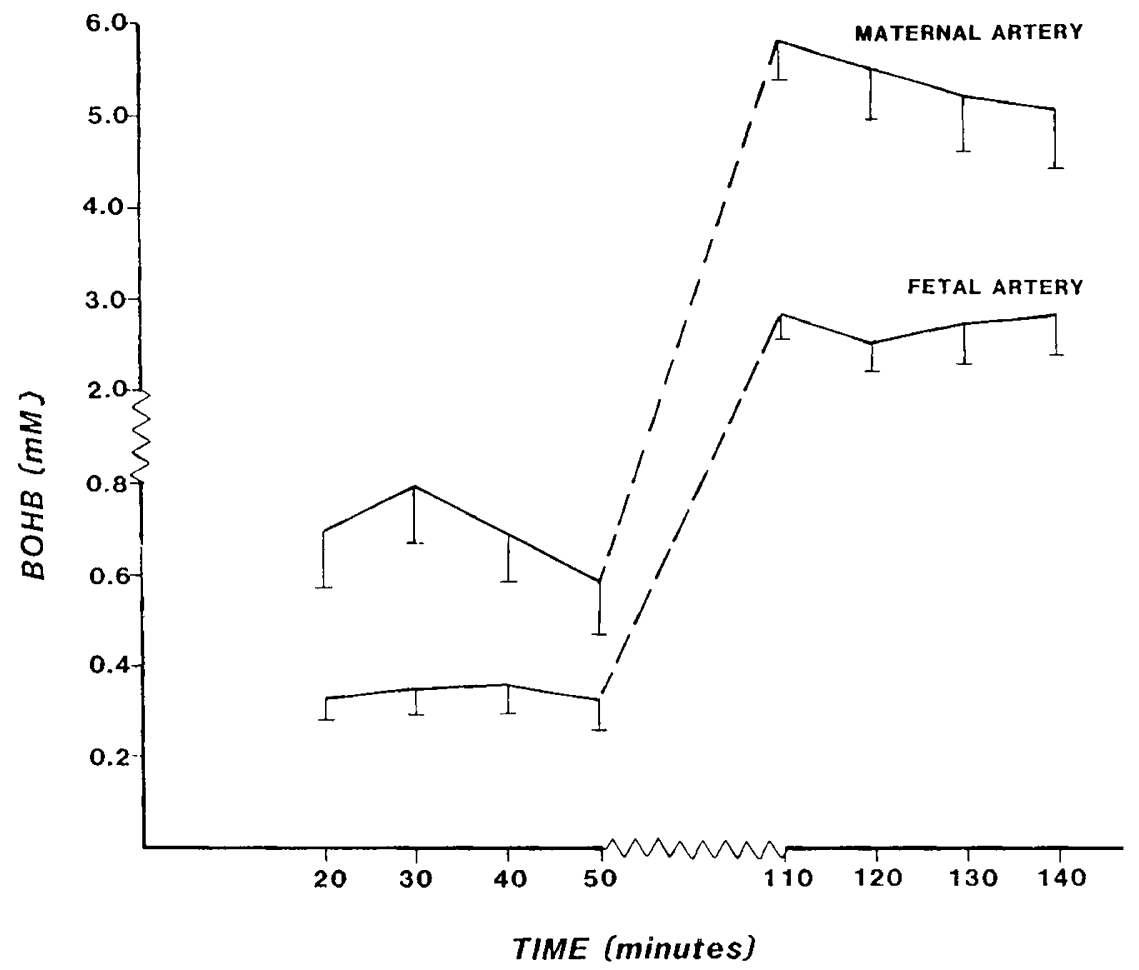

Fig. 1. Fetal and maternal levels of $\mathrm{BOHB}$ before and during maternal infusion of $\mathrm{NaBOHB}$ (mean $\pm \mathrm{SEM}$ ). 
Table 6. Species differences in maternal:fetal ratios of ketones in this study and from literature review*

\begin{tabular}{|c|c|c|c|c|c|}
\hline & \multicolumn{2}{|c|}{$\mathrm{BOHB}(\mathrm{mM})$} & \multicolumn{2}{|c|}{ Ketones (mM) } & \multirow{2}{*}{$\begin{array}{c}\text { Ratio } \\
\text { (maternal/fetal) }\end{array}$} \\
\hline & Maternal & Fetal & Maternal & Fetal & \\
\hline \multirow[t]{4}{*}{ Present study (baboon) } & $0.70 \pm 0.21$ & $0.38 \pm 0.10$ & & & 1.84 \\
\hline & & & $1.04 \pm 0.26$ & $0.53 \pm 0.13$ & 1.96 \\
\hline & $5.42 \pm 0.93$ & $3.08 \pm 0.73$ & & & 1.76 \\
\hline & & & $7.06 \pm 1.11$ & $3.87 \pm 0.73$ & 1.82 \\
\hline \multirow[t]{2}{*}{ Paterson et al. (4) (human) } & & & $0.93 \pm 0.19$ & $0.47 \pm 0.11$ & 1.98 \\
\hline & & & 1.81 & 0.78 & 2.32 \\
\hline $\begin{array}{l}\text { Aynsley-Green et al. (17) (hu- } \\
\text { man) }\end{array}$ & & & $0.49 \pm 0.06$ & $0.25 \pm 0.03$ & 1.96 \\
\hline \multirow[t]{2}{*}{ Morriss et al. (5) (sheep) } & $0.602 \pm 0.072$ & $0.082 \pm 0.003$ & & & 7.43 \\
\hline & $1.208 \pm 0.123$ & $0.118 \pm 0.008$ & & & 10.23 \\
\hline \multirow{3}{*}{$\begin{array}{l}\text { Miodovnik et al. }(16,22,25) \\
\text { (sheep) }\end{array}$} & $0.76 \pm 0.20$ & $0.01 \pm 0.01$ & & & 7.80 \\
\hline & $0.49 \pm 0.14$ & $0.12 \pm 0.08$ & & & 4.08 \\
\hline & $5.93 \pm 1.32$ & $0.15 \pm 0.03$ & & & 39.53 \\
\hline
\end{tabular}

$*$ All values expressed as mean $\pm \mathrm{SEM}$.

an absence of BOHB-induced stress hyperglycemia. The rise in lactate and fall in $\mathrm{PO}_{2}$ are similar to results induced by infusion of hypertonic glucose into the fetal lamb (17-20). These changes, although similar to those induced by asphyxia, are not asphyxiainduced in these experiments, as indicated by umbilical blood flow and fetal oxygen consumption data (6).

As an explanation for the low umbilical vein fetal $\mathrm{PO}_{2}$, Clark et al. (21) demonstrated increased oxygen extraction by the sheep placenta. This is compatible with our data in that fetal oxygen extraction was maintained in the presence of somewhat decreased umbilical vein $\mathrm{PO}_{2}(p<0.1>0.05)$. The umbilical blood flows were variable in this acute preparation and we could not definitively measure significantly decreased fetal oxygen delivery, although seven of eight animals had decreased umbilical vein oxygen content, six of eight had decreased umbilical vein blood flow, and six of eight had decreased computed oxygen delivery during $\mathrm{NaBOHB}$ infusion. The absence of change in fetal and maternal $\mathrm{pH}$ usually associated with increased levels of lactate is probably related to the fact that $\mathrm{BOHB}$ was infused as the sodium salt. In a chronic fetal sheep preparation in which $\beta$-hydroxybutyrate was infused to the mother, mild maternal alkalosis was a consequence (22). Therefore, we believe that this technique permits the evaluation of the effects of ketones without the additional effects of acidosis.

Changes in endogenous substrate levels noted in these fetuses are associated with the decreased fetal $\mathrm{PO}_{2}$ after ketone infusion. The above normal fetal $\mathrm{PaO}_{2}$ before infusion allows examination of relative changes in fetal $\mathrm{PaO}_{2}$ and oxygen delivery without the superimposition of the effects of reduced oxygenation-anaerobic metabolism and metabolic and physiologic decompensation. The increases in lactate and pyruvate in the fetus may be related to placental metabolism of BOHB (23). The small, but significant changes in maternal lactate and pyruvate could relate to continuing anesthetic and surgical stress as well. Of interest is the fact that glycerol levels did not rise, indicating that stress induced lipolysis was minimal. Inhibition of lipolysis by ketones may be an explanation for the lack of change in glycerol levels during anesthetic and infusion stress (24). Previous investigators, working with other animal models, have demonstrated that the placenta is the most active site of ketone body oxidation (23). It is likely, therefore, that the placental utilization of ketones is responsible for the decreased $\mathrm{PO}_{2}$ of fetal blood during ketone body infusion (25). The fetus itself does not increase oxygen utilization during the uptake of large quantities of $\beta$-hydroxybutyrate. It must be assumed, therefore, that ketones are taken up by the fetal primate to be used for fat synthesis, a major nonoxidative pathway of ketone body utilization (24). The utilization of ketones for lipogenesis has been documented in the fetal rat. Also, the necessary enzymatic pathways for lipogenesis from ketones are present in human fetal tissue.
In conclusion, the placenta appears more permeable to $\mathrm{BOHB}$ in the baboon and in humans than in the sheep. No significant contribution of $\mathrm{BOHB}$ to fetal oxidative metabolism could be identified; BOHB may, however, contribute to fetal lipid energy stores (23). Why placental transport of BOHB is so different as well as the role of higher levels of BOHB in the primate fetus compared to the sheep remains to be elucidated. Studies using chronically maintained ketoacidosis and the use of isotopelabeled ketone substrates may contribute to our understanding of maternal-fetal ketone dynamics.

Acknowledgments. The authors acknowledge the technical assistance of Nanci Hackl and Audrey Paton, the support of the Department of Laboratory Animal Medicine, and the secretarial support of Rose Scott and Rose Carpenter.

\section{REFERENCES}

1. Horton WT, Sadler TW 1983 Effects of maternal diabetes on early embryogenesis: alternations in morphogenesis produced by the ketone body, $\beta$ hydroxybutyrate. Diabetes 32:610-616

2. Drury MJ, Green AT, Stronge JM 1977 Pregnancy complicated by clinical diabetes mellitus. Obstet Gynecol 49:519

3. Pedersen J, Pedersen LJ, 1965 Prognosis of the outcome of pregnancies in diabetes. Acta Endocrinol (Copenh) 50:70 78

4. Paterson P, Sheath J, Taft P, Wood C 1967 Maternal and fetal ketone concentrations in plasma and urine. Lancet 1:862-865

5. Morriss FH, Boyd RDH, Makowski EL, Meschia G, Battaglia FC 1974 Umbilical A-V differences of acetate and betahydroxybutyrate in fed and starved ewes. Proc Soc Exp Biol Med 145:879-883

6. Behrman RE, Lees MH, Peterson EN, deLannoy CW, Seeds AE 1970 Distribution of the circulation in the normal and asphyxiated fetal primate. Am J Obstet Gynecol 108:956-969

7. Paton JH, Fisher DE, deLannoy CW, Behrman RE 1973 Umbilical blood flow, cardiac output and organ blood flow in the immature baboon fetus. Am J Obstet Gynecol 117:560-566

8. Paton JB, Fisher DE 1984 Organ blood flows of fetal and infant baboons. Early Hum Dev 10:137-147

9. Laurel S, Tibbling G 1966 An enzymatic fluorometric micromethod for the determination of glycerol. Clin Chim Acta 13:317-322

10. Loomis ME 1961 An enzymatic fluorometric method for the determination of lactic acid in serum. J Lab Clin Med 57:1421-1429

11. Karl IE, Pagliara AS, Kipnis DM 1972 A microfluorometric enzymatic assay for the determination of alanine and pyruvate in plasma and tissue. J Lab Clin Med 80:434-441

12. Persson B 1969 Determination of plasma acetoacetate and D-beta-hydroxybutyrate in newborn infants by an enzymatic fluorometric micro-method. Scand J Clin Lab Invest 25:9-18

13. Levitsky LL, Paton JB, Fisher DE, deLannoy CW 1980 Arterial blood levels of energy substrates and evidence for renal glucose production in the baboon infant. Pediatr Res 14:926-931

14. Deleted in proof.

15. Sokal RR, Rohlf FJ 1981 Biometry. WH Freeman and Co., New York

16. Miodovnik M, Lavin JP, Harrington DJ, Leung LS, Seeds AE, Clark KE 1982 Effects of maternal ketoacidemia on the pregnant ewe and the fetus. Am J Obstet Gynecol 144:585-593

17. Aynsley-Green A, Soltesz G, Jenkins PA, Mackenzie IZ 1985 The metabolic 
and endocrine milieu of the human fetus at 18-21 weeks of gestation: II: blood glucose, lactate, pyruvate and ketone body concentrations. Biol Neonate 47:19-25

18. Robillard JE, Sessions C, Kennedy RL, Smith FG 1978 Metabolic effects of constant hypertonic glucose infusion in well-oxygenated fetuses. Am J Obstet Gynecol 130:199-203

19. Phillips AF, Rosenkrantz TS, Forte PJ, Raye JR 1985 The effects of chronic hyperglycemia on substrate uptake by the ovine fetus and conceptus. Pediatr Res 19:659-666

20. Crandell SS, Fisher DJ, Morriss FH 1985 Effects of ovine maternal hyperglycemia on fetal regional blood flows and metabolism. Am J Physiol 249:E454E460
21. Clark KE, Skillman CA, Mack C, Meyer K 1984 Placental metabolism of betahydroxybutyrate produced fetal hypoxia. Soc Gynecol Invest(abstr):19 22. Miodovnik M, Skillman CA, Hertzberg V, Harrington DJ, Clark KE 1986 Effect of maternal hyperketonemia in hyperglycemic pregnant ewes and their fetuses. Am J Obstet Gynecol 154:394-401

23. Robinson AM, Williamson DH 1980 Physiological roles of ketone bodies as substrates and signals in mammalian tissues. Physiol Rev 60:143-187

24. Shambaugh GE III 1985 Ketone body metabolism in the mother and fetus. Fed Proc 44:2347-2351

25. Miodovnik M, Lavin JP, Harrington DJ, Leung LS, Seeds AE, Clark KE 1982 Cardiovascular and biochemical effects of infusion of betahydroxybutyrate into the fetal lamb. Am J Obstet Gynecol 144:594-600 